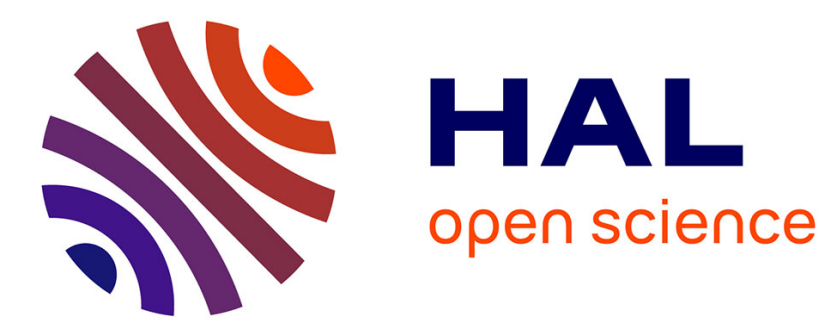

\title{
Organocatalysts for the synthesis of poly(ethylene terephthalate-co-isosorbide terephthalate): a combined experimental and DFT study
}

Nicholas Stanley, Thomas Chenal, Nicolas Jacquel, René Saint-loup, Joao

Paulo Prates Ramalho, Philippe Zinck

\section{To cite this version:}

Nicholas Stanley, Thomas Chenal, Nicolas Jacquel, René Saint-loup, Joao Paulo Prates Ramalho, et al.. Organocatalysts for the synthesis of poly(ethylene terephthalate-co-isosorbide terephthalate) : a combined experimental and DFT study. Macromolecular Materials and Engineering, 2019, Macromolecular Materials and Engineering, 304 (9), pp.1900298. 10.1002/mame.201900298 . hal-03246278

\section{HAL Id: hal-03246278 \\ https://hal.univ-lille.fr/hal-03246278}

Submitted on 2 Jun 2021

HAL is a multi-disciplinary open access archive for the deposit and dissemination of scientific research documents, whether they are published or not. The documents may come from teaching and research institutions in France or abroad, or from public or private research centers.
L'archive ouverte pluridisciplinaire HAL, est destinée au dépôt et à la diffusion de documents scientifiques de niveau recherche, publiés ou non, émanant des établissements d'enseignement et de recherche français ou étrangers, des laboratoires publics ou privés. 


\section{Organocatalysts for the synthesis of poly(ethylene terephthalate-co-isosorbide}

terephthalate) : a combined experimental and DFT study

N. Stanley, ${ }^{1}$ T. Chenal, ${ }^{1}$ N. Jacquel, ${ }^{2}$ R. Saint-Loup, ${ }^{2}$ J.P. Prates Ramalho ${ }^{3}$, P. Zinck ${ }^{1 *}$

1 Univ. Lille, CNRS, Centrale Lille, ENSCL, Univ. Artois, UMR 8181 - UCCS - Unité de Catalyse et Chimie du Solide, F-59000 Lille, France, philippe.zinck@univ-lille.fr 2 Roquette Frères, F-62080 Lestrem Cedex, France

3 Chemistry Department, CQE - Évora Chemistry Centre and Hercules Centre, Sciences and Technology School, University of Évora, Rua Romão Ramalho 59, 7000-671 Évora, Portugal 


\begin{abstract}
Organocatalysts are assessed for the insertion of isosorbide, a rigid, biobased diol monomer, into poly(ethylene terephthalate). A sulfonic acid (p-toluenesulfonic acid - APTS), an amidine base (1,8-diazabicyclo [5.4.0] undec-7-ene - DBU) and a guanidine base (1,5,7-triazabicyclo[4.4.0]dec5-ene - TBD) successfully catalyse the polymerization. The reaction mechanisms are studied by DFT (Density Functional Theory). A bifunctional activation is observed in the presence of the sulfonic acid, the carbonyl moiety being activated via the acidic proton of APTS and the alcohol via the basic oxygen. Regarding DBU, a mechanism based on a basic activation of the alcohol rather than a nucleophilic attack of the catalyst is evidenced. The difference observed between TBD and DBU is attributed to a better H-bonding ability of the former $v s$. the latter.
\end{abstract}




\section{Introduction}

The use of biobased monomers as feedstock for the synthesis of polymers is a growing field, motivated by both environmental concerns and the decrease of the world oil reserves. Of particular interest is the use of renewables molecules that bring new properties to the polymer or that improve existing ones. Isosorbide, for example, can lead to improved thermal and mechanical properties in the fields of coating or for the packaging of liquid. ${ }^{[1]}$ This biobased diol, belonging to the family of 1,4:3,6-dianhydrohexitols, has been used as comonomer for the synthesis of various polycondensates such as aliphatic ${ }^{[1]}$ and furanoate polyesters, ${ }^{[2-4]}$ oligo/polyethers, ${ }^{[5-6]}$ and polycarbonates ${ }^{[7-8-9]}$ for instance. The insertion of the harmless isosorbide into poly(ethylene terephthalate) (PET) has also been reported, ${ }^{[10-15]}$ leading to an increase of the glass transition temperature (Tg) of the polymer, which can lead to new field of applications such as hot filling. Antimony based catalytic systems are suitable for the synthesis of poly(ethylene terephthalate-coisosorbide terephthalate) polymers (PEIT). ${ }^{[16-17]}$ Antimony resources are however known to be scarce, ${ }^{[18]}$ and the search for alternative catalytic systems is interesting in this frame.

Organocatalysis for polymerization reactions is a field that has gained a huge interest these last 1520 years, notably in a sustainable chemistry background. ${ }^{[19-23]}$ Most of the studies were devoted to chain growth reactions, especially the ring-opening polymerization of various type of heterocycles and the polymerization of acrylic and methacrylic monomers. Step-growth reactions were substantially less studied. Recent efforts were oriented toward organocatalysed syntheses of polyurethanes, ${ }^{[24-27]}$ while the assessment of sulfuric and phosphoric acids as catalysts for the polycondensation of lactic acid was already reported in the nineties. ${ }^{[28]}$ Various triflate (trifluoromethansulfonate) salts as bi-components dual organocatalytic systems were also assessed for the step-growth synthesis of polylactide. ${ }^{[29]}$ The depolymerization of poly(ethylene terephthalate) triggered by organocatalysts has been reported in the literature, ${ }^{[30]}$ together with its 
synthesis. ${ }^{[31-32]}$ The research on catalytic systems for the synthesis of PEIT has in turn mainly focused on bimetallic combinations. ${ }^{[16-17 ; 33-34]}$ To the best of our knowledge, organocatalysts have never been assessed for this purpose. We report herein the use of various acids and bases represented in Scheme 1 as organocatalysts for the synthesis of PEIT together with DFT studies of the catalytic mechanisms involved. 


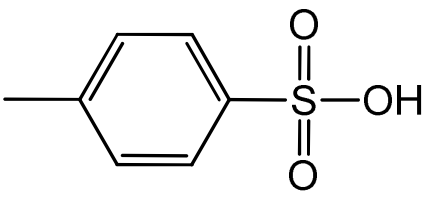

p-toluene sulfonic acid (APTS)

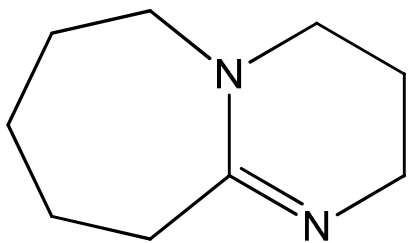

1,8-diazabicyclo [5.4.0] undec-7-ene

(DBU)<smiles>O=P(O)(O)O</smiles>

phosphoric acid $\left(\mathrm{H}_{3} \mathrm{PO}_{4}\right)$<smiles></smiles>

diphenyl phosphate (DPP)<smiles>C1CN=C2NCCCN2C1</smiles>

1,5,7-triazabicyclo[4.4.0]dec-5-ene (TBD)<smiles>CCN(CC)P1(=NC(C)(C)C)N(C)CCCN1C</smiles>

2-tert-butylimino-2-diethylamino-1,3dimethylperhydro-1,3,2-diazaphosphorine (BEMP)

Scheme 1. Acids and bases used as catalysts in this study 


\section{Experimental section}

\subsection{Materials}

Terephthalic acid, p-toluenesulfonic acid (APTS), diphenylphosphate (DPP), 1,8-diazabicyclo [5.4.0] undec-7-ene (DBU) and 2-tert-butylimino-2-diethylamino-1,3-dimethylperhydro-1,3,2diazaphosphorine (BEMP) were supplied by Acros Organic. Ethylene glycol and 1,5,7triazabicyclo[4.4.0]dec-5-ene (TBD) were supplied by Sigma Aldrich. Phosphoric acid was supplied by Carlo Erba. Isosorbide commercialized under the trade name Polysorb P was supplied by Roquette Frères (Lestrem, France). Irgamod 195, a calcium phosphonate stabilizer used as antioxidant was kindly supplied by BASF.

\subsection{Oligomer synthesis}

Ethylene glycol (1041.9 g, $16.8 \mathrm{~mol})$, isosorbide (350.5 g, 2.4 mol.), terephthalic acid (2656.1 g, 16 mol.), sodium acetate $(0.181 \mathrm{~g})$ and Irgamod $195(0.35 \mathrm{~g})$ are introduced in a $7.5 \mathrm{~L}$ stainlesssteel batch reactor equipped with a heating system, a mechanical stirrer with torque measurement, a distillation column, a vacuum line and a nitrogen-gas inlet. The system is placed under inert gas (oxygen is removed from the reactor) via 4 cycles of vacuum/ nitrogen gas at between 60 and $80^{\circ} \mathrm{C}$. The reaction medium is then heated to $260^{\circ} \mathrm{C}$ under 5.7 bars of pressure whilst under constant stirring at $150 \mathrm{rpm}$. The rate of esterification is estimated by the quantity of distillate collected. Once the esterification is finished, the oligomers are recovered, cooled and ground.

\subsection{Polymer synthesis}

PEIT oligomers synthetized in the previous step (40 g) are introduced in a glass reactor and the system is sealed. The apparatus is equipped with a heating system, a mechanical stirrer with torque 
measurement, a vacuum line and a nitrogen-gas inlet. The reactor is placed under inert gas via three cycles of vacuum/argon and heated to $240^{\circ} \mathrm{C}$ to melt the oligomers. Whilst performing the cycles of vacuum/argon, the catalyst is placed in ethylene glycol $(1 \mathrm{~mL})$ and stirred under argon to form the catalytic solution. Once the oligomers have melted, the catalytic solution is added to the system. At this point, the reactor is simultaneously heated to $260^{\circ} \mathrm{C}$ whilst stirring at $50 \mathrm{rpm}$ is applied. When applying the stirring, the viscosity of the reaction medium begins to be measured on a computer using the program "labworld soft". The reactor is then slowly placed under vacuum during approximately 40 minutes, reaching pressures of less than 0.1 mbar. The reaction can begin at less than 0.5 mbar which is normally reached at 30 minutes. The reaction was stopped after 3 hours except for entries 5 and 7, where the viscosity became too high after $c a$. 80/90 min. Once the reaction is finished, the polymer is recovered and placed on a metal surface to cool.

\subsection{Analyses}

Viscosimetry analyses were performed using an automated Ubbelohde capillary system at $35^{\circ} \mathrm{C}$. Samples were prepared at concentrations of $5 \mathrm{~g} / \mathrm{L}$ in 2 -chlorophenol, heated at $135^{\circ} \mathrm{C}$ for 2 hours with stirring to aid with dissolution before filtration. The reduced viscosity of the samples was calculated using the following equation:

$$
\eta_{\text {red }}=\frac{t-t_{s}}{t_{s} \cdot C}
$$

where $t$ is the time of the analysis for the sample, $t_{s}$ is the time of the analysis for the pure solvent and $\mathrm{C}$ is the concentration of the sample.

Size exclusion chromatography was performed using a mixture of chloroform and 1, 1, 1, 3, 3, 3 hexafluoro-2-propanol (95:5 vol. \%) on Agilent Technologies 1260 Infinity with Shodex column chromatography (K-G, K804 and K802.5). Samples with a concentration of $5 \mathrm{~g} / \mathrm{L}$ were injected 
under a flow rate $1 \mathrm{~mL} / \mathrm{min}$. Signals were detected using a refractive index (RI) detector calibrated using PMMA standards (3070 g/mol, $7360 \mathrm{~g} / \mathrm{mol}, 18500 \mathrm{~g} / \mathrm{mol}, 68800 \mathrm{~g} / \mathrm{mol}$ and $211000 \mathrm{~g} / \mathrm{mol})$. DSC analyses were performed under nitrogen atmosphere using a Q20 TA instrument, using the following cycles: cool down to $0^{\circ} \mathrm{C}$ at $20^{\circ} \mathrm{C} / \mathrm{min}$, heat to $280^{\circ} \mathrm{C}$ at $20^{\circ} \mathrm{C} / \mathrm{min}$ (first heat), cool down to $0^{\circ} \mathrm{C}$ at $20^{\circ} \mathrm{C} / \mathrm{min}$, heat up to $280^{\circ} \mathrm{C}$ at $20^{\circ} \mathrm{C} / \mathrm{min}$ (second heat).

${ }^{1} \mathrm{H}$ NMR spectra of the polymers were recorded on a Bruker Avance $300 \mathrm{MHz}$ instrument at 300 $\mathrm{K}$ using a mixture of deuterated chloroform and deuterated trifluoroacetic acid (3:1 vol. \%). The chemical shifts were calibrated using the residual resonances of the solvent (chloroform at 7.26 ppm).

Colorimetry analyses were performed using an Agilent Cary 60 spectrophotometer. All samples were prepared at concentrations of $50 \mathrm{~g} / \mathrm{L}$ using a mixture of chloroform and 1, 1, 1, 3, 3, 3 hexafluoro-2-propanol (95:5 vol. \%). Values were measured using a standard illuminant $\mathrm{C}$ light source at 2 degrees. The yellowness index YI was calculated using the following equation:

$$
Y I=\frac{100\left(C_{x} X-C_{z} X\right)}{Y}
$$

where $\mathrm{X}, \mathrm{Y}$ and $\mathrm{Z}$ are the $\mathrm{CIE}$ tristimulus values obtained during analyses. $\mathrm{Cx}$ and $\mathrm{Cz}$ are coefficients depending on the illuminant and observer used. For this study, $\mathrm{Cx}=1.2769$ and $\mathrm{Cz}=$ 1.0592.

\subsection{Calculation details}

All density functional theory (DFT) calculations were performed with the Gaussian 16 package. ${ }^{[35]}$ Geometries optimizations for the reactants, products and transition states, followed by vibrational frequency calculations, were performed by using the hybrid meta-GGA M06-2X functional ${ }^{[36]}$ with the 6-31G(d,p) basis set. Each optimized geometry was confirmed as an energy minimum for 
reactants and products, by the absence of imaginary frequencies and for transition states by possessing a single imaginary frequency. Single point energies were subsequently calculated for all structures, with the same functional and the much larger aug-cc-pVTZ basis set. 


\section{Results and discussion}

The synthesis of PEIT involves three steps that are represented in Scheme 2. First, an esterification between terephtalic acid and the diols leads to oligomers, that are further transesterified to lead to a polymer. The last step is the solid state postcondensation conducted between the glass transition and the melting temperatures to afford high molecular weight polymers. Our study is devoted to the catalysis of the intermediate transesterification reaction. A batch of oligomers was synthesized according to the procedure reported in the experimental part and used as starting material. The reaction was stopped after 3 hours except for entries 5 and 7, where the viscosity became too high after $c a .80 / 90 \mathrm{~min}$. Results of the synthesis of poly(ethylene terephthalate-co-isosorbide terephthalate) starting from the oligomers and using phosphoric and sulfonic acids are presented in Table 1, entries 2-7. p-toluenesulfonic acid (entry 2) leads to a number-average molecular weight of $c a .24000 \mathrm{~g} / \mathrm{mol}$ after $3 \mathrm{~h}$ reactions, a value significantly higher than that obtained without catalyst (entry 1). The ${ }^{1} \mathrm{H}$ NMR spectrum of the PEIT resulting from entry 2 is presented in Figure 1. The signals characteristic of isosorbide can be seen in addition to the main PET signals. The percentage of isosorbide in the copolymer can be determined from the protons $\mathbf{2}$ and $\mathbf{5}$, leading to $8.7 \%$ (see annex for calculation details). Diethylene glycol units can also be noticed and determined at $c a .10 \%$ from the $\mathbf{D}$ protons (see annex for calculation details). These units result from the etherification of two ethylene glycol units. They bring flexibility and tend to decrease the glass transition temperature of the polymer, ${ }^{[37]}$ which was found around $80^{\circ} \mathrm{C}$, lower than that of the polymer obtained without catalyst (entry 1) and containing 5\% DEG. The presence of $10 \%$ DEG units in addition to the $8.7 \%$ isosorbide units hampers the crystallization, leading to a fully amorphous polymer. Significant coloration of the polymer can also be noticed, with a high yellowing index of 14.6. 

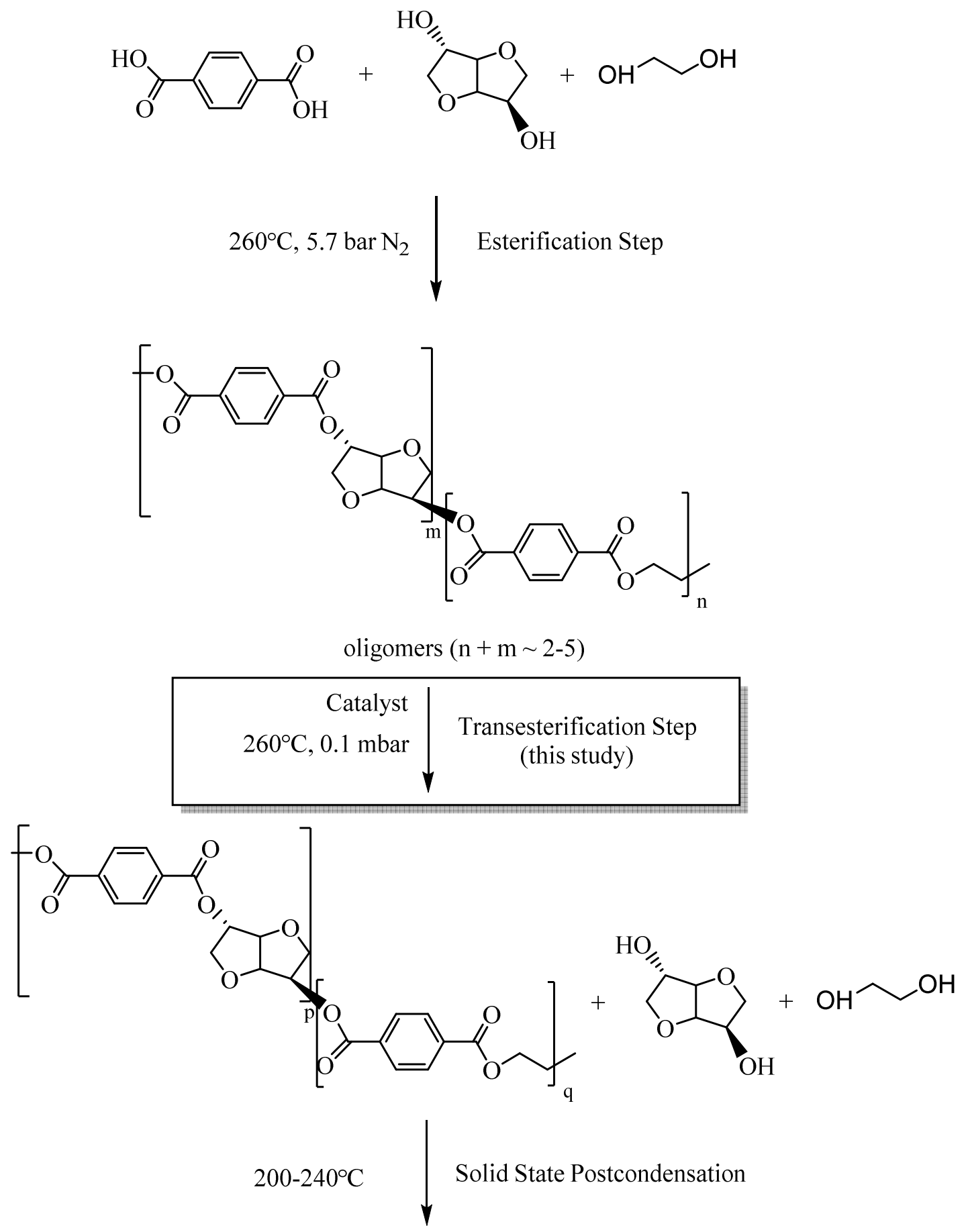

High molecular weight polymer

Scheme 2. Synthesis of PEIT in 3 steps 


\begin{tabular}{|c|c|c|c|c|c|c|c|c|c|c|c|c|c|}
\hline Entry & Cata. & $\begin{array}{l}\text { Amount } \\
(\mathrm{mol} \%)\end{array}$ & $\begin{array}{c}\text { Isb }^{\mathbf{a})} \\
(\mathrm{mol} \%)\end{array}$ & $\begin{array}{c}\text { DEG }^{\mathbf{b})} \\
(\operatorname{mol} \%)\end{array}$ & $\begin{array}{c}\left.\eta_{\text {red }}{ }^{c}\right) \\
(\mathrm{mL} / \mathrm{g})\end{array}$ & $\begin{array}{c}\left.M_{n}{ }^{d}\right) \\
(g / m o l)\end{array}$ & $\bigoplus_{m}{ }^{d)}$ & $\begin{array}{l}\left.\mathbf{T}_{\mathrm{g}}^{\mathrm{e}}\right) \\
\left({ }^{\mathrm{o}} \mathrm{C}\right)\end{array}$ & $\begin{array}{l}\mathbf{T}_{\mathbf{m}}{ }^{\mathbf{e})} \\
\left({ }^{\mathbf{o}} \mathbf{C}\right)\end{array}$ & $\mathbf{L} * \mathbf{f})$ & $\left.a^{* g}\right)$ & $\mathbf{b}^{* h)}$ & $\mathbf{Y I}^{\mathbf{i})}$ \\
\hline 1 & - & - & 8.2 & 4.9 & 27.3 & 10800 & 2.07 & 83 & 230 & 97.9 & -0.1 & 3.7 & 6.2 \\
\hline 2 & APTS & 1 & 8.7 & 10.0 & 57.7 & 24300 & 2.16 & 80 & - & 95.6 & 1.1 & 8.2 & 14.6 \\
\hline 3 & $\mathrm{H}_{3} \mathrm{PO}_{4}$ & 1 & 7.9 & 5.0 & 21.7 & 9500 & 1.89 & 74 & 230 & 98.5 & -0.2 & 2.9 & 4.8 \\
\hline 4 & $\mathrm{H}_{3} \mathrm{PO}_{4}$ & 2 & 8.0 & 3.8 & 36.2 & 16300 & 2.06 & 76 & 229 & 98.6 & -0.2 & 2.6 & 4.3 \\
\hline 5 & $\mathrm{H}_{3} \mathrm{PO}_{4}$ & 5 & $\mathrm{nd}^{\mathrm{j}}$ & $\mathrm{nd}^{\mathrm{j}}$ & $\mathrm{nd}^{\mathrm{j}}$ & $\mathrm{nd}^{\mathrm{j}}$ & $\mathrm{nd}^{\mathrm{j}}$ & 75 & 208 & $\mathrm{nd}^{\mathrm{j}}$ & $\mathrm{nd}^{\mathrm{j}}$ & $\mathrm{nd}^{\mathrm{j}}$ & $\mathrm{nd}^{\mathrm{j}}$ \\
\hline 6 & DPP & 1 & 7.9 & 4.9 & 24.0 & 10200 & 1.95 & 75 & 227 & 98.2 & 0.1 & 2.5 & 4.4 \\
\hline 7 & DPP & 5 & $\mathrm{nd}^{\mathrm{j}}$ & $\mathrm{nd}^{\mathrm{j}}$ & $\mathrm{nd}^{\mathrm{j}}$ & $\mathrm{nd}^{\mathrm{j}}$ & $\mathrm{nd}^{\mathrm{j}}$ & 82 & 215 & $\mathrm{nd}^{\mathrm{j}}$ & $\mathrm{nd}^{\mathrm{j}}$ & $\mathrm{nd}^{\mathrm{j}}$ & $\mathrm{nd}^{\mathrm{j}}$ \\
\hline 8 & DBU & 2 & 8.1 & 2.5 & 38.7 & 17700 & 2.36 & 83 & 233 & 97.6 & 0.1 & 5.1 & 8.8 \\
\hline 9 & TBD & 2 & 8.1 & 1.9 & 51.7 & 23000 & 1.97 & 86 & 234 & 96.5 & 0.9 & 9 & 15.6 \\
\hline 10 & BEMP & 2 & 7.9 & 2.8 & 33.2 & 9500 & 2.79 & 79 & 235 & 96.6 & 1.0 & 7.6 & 13.5 \\
\hline 11 & $\mathrm{Sb}_{2} \mathrm{O}_{3}$ & 250 wt. ppm & 9.2 & 1.9 & 102.7 & 34400 & 2.07 & 91 & 227 & 98.4 & -1.4 & 3.3 & 5.1 \\
\hline
\end{tabular}

Table 1. Microstructure, reduced viscosity, molecular weight, thermal properties and colorimetry analyses of PEIT synthetized using organocatalysts. a) isosorbide content measured by ${ }^{1} \mathrm{H}$ NMR. b) diethylene glycol content measured by ${ }^{1} \mathrm{H}$ NMR. ${ }^{\text {c) }}$ reduced viscosity.measured by a Ubbelohde capillary system. ${ }^{\text {d) }}$ number average molecular weight and dispersity measured by size exclusion chromatography in a 95/5 chloroform / 1, 1, 1, 3, 3, 3 hexafluoro-2-propanol (HFIP) mixture using PMMA standards. ${ }^{\text {e) }}$ Glass transition and melting temperatures measured by DSC. ${ }^{\text {f) }}$ Whiteness of the polymer. ${ }^{\text {g) }}$ Colour of the polymer in the range of green (negative values) to red (positive values). ${ }^{\text {h) }}$ Colour of the polymer in the range of blue (negative values) to yellow (positive values). ${ }^{\text {i) }}$ Yellowness index (see experimental part). ${ }^{\mathrm{j})}$ non determined, the polymers were partially soluble only 

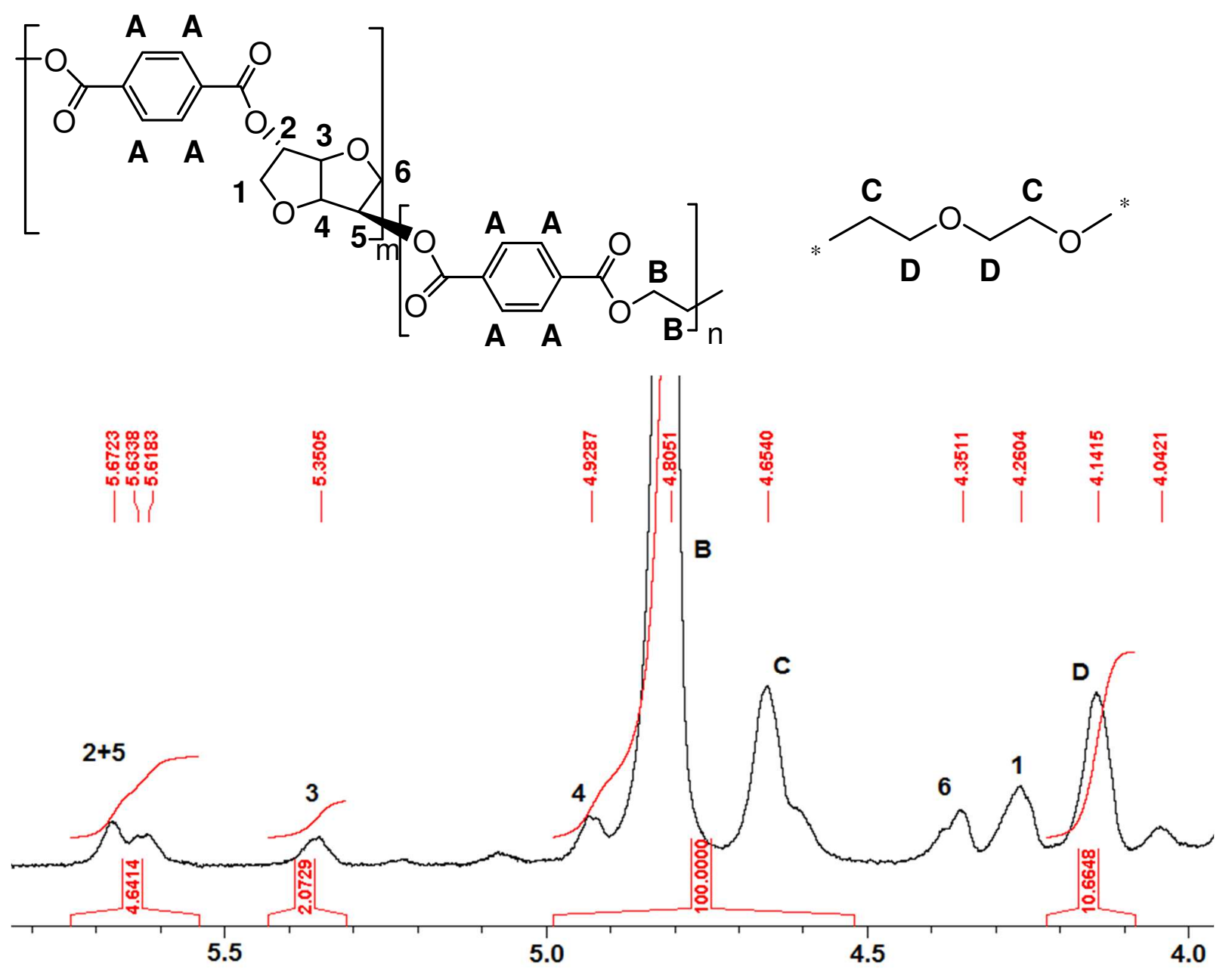

Figure 1. ${ }^{1} \mathrm{H}$ NMR spectra of a typical PEIT (entry 2) at $300 \mathrm{MHz}$ in a mixture of deuterated chloroform and deuterated trifluoroacetic acid (3:1 vol\%) in the 4-6 ppm zone and assignments.

Phosphoric acid was then assessed as a catalyst (entry 3-5). A loading of $1 \mathrm{~mol} \%$ leads to polymer properties slightly lower than those observed without catalyst, highlighting no significant catalyst activity and possibly weak degradation reactions. It should be noticed here that phosphorous compounds are generally considered as stabilizers in these reactions ${ }^{[38]}$ An increase of the catalytic loading to $2 \%$ leads to a molecular weight of $16300 \mathrm{~g} / \mathrm{mol}$, highlighting a catalytic activity. This is accompanied by a lower DEG content and better coloration than those observed for the polymer 
obtained using p-toluenesulfonic acid at $1 \mathrm{~mol} \%$, but also a lower glass transition temperature. The amount of isosorbide inserted in the polymer is slightly lower compared to APTS, $c a$. $8.0 \% v s$. 8.7\%. The higher amount of DEG observed in the case of p-toluene sulfonic acid vs. phosphorous catalyst may be attributed to the higher acidity of the sulfur based catalyst $v s . \mathrm{H}_{3} \mathrm{PO}_{4}(\mathrm{pKa}=-3$ in $\mathrm{H}_{2} \mathrm{O} v$ s. 2.15 for $\left.\mathrm{H}_{3} \mathrm{PO}_{4}\right){ }^{[39]}$ The lower $\mathrm{T}_{\mathrm{g}}$ obtained using the phosphorous catalyst may in turn be linked to the lower molecular weight obtained.

The catalyst loading was then increased to $5 \%$ phosphoric acid (entry 5). This leads to a material that is not soluble in the solvents used for the analyses. A possible explanation is a cross-linking side reaction via the phosphorous compound, as tentatively represented in Scheme 3. Pencszek et $a l$. reported indeed the reaction of ethylene glycol with phosphorous acid to form phosphorous esters. ${ }^{[40-41]}$ Their analyses by ${ }^{31} \mathrm{P}$ NMR showed the presence of various species theorized to be phosphorous mono, di and tri-ester compounds. A reticulation via opening of isosorbide rings may also not be fully discarded. Diphenylphosphate was also assessed as potential organocatalyst. At $1 \%$, the performances are similar to those observed using $\mathrm{H}_{3} \mathrm{PO}_{4}$. At $5 \mathrm{~mol} \%$, if unsoluble materials are also obtained, slightly different thermal properties are observed. The poly(ethylene terephatalate-co-isosorbide terephthalate) shows higher glass transition and melting temperatures.

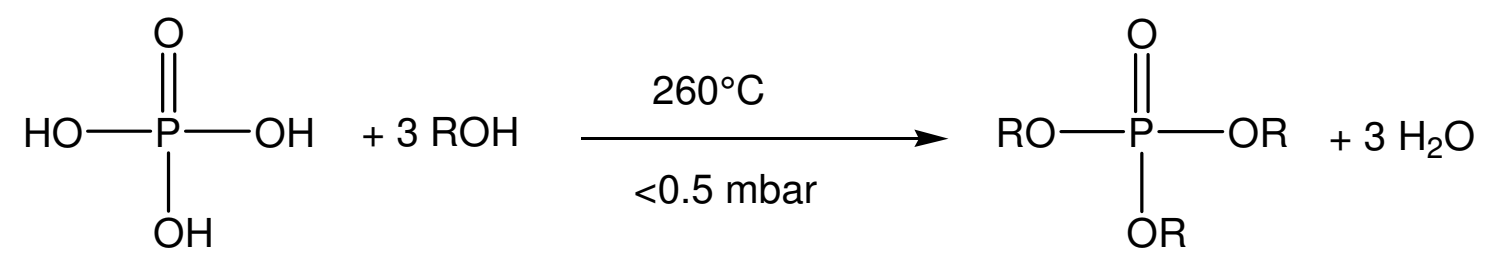

Scheme 3. Hypothetical polymer branching leading to cross-linking with phosphorous compounds 
DFT studies were performed in order to clarify the APTS catalyzed reaction mechanism. Phosphorous catalysts were not considered due to a lower catalytic activity in addition to the occurrence of side reactions. The transesterification of diethylterephtalate by ethanol (Scheme 4) was considered as a model for the reaction as already done in the literature for metal based catalysts. ${ }^{[42]}$ Regarding transesterification catalysed by a sulfonic acid, a two steps reaction adapted from the sulfonic acid catalysed ring-opening polymerization of lactone ${ }^{[43]}$ was considered.

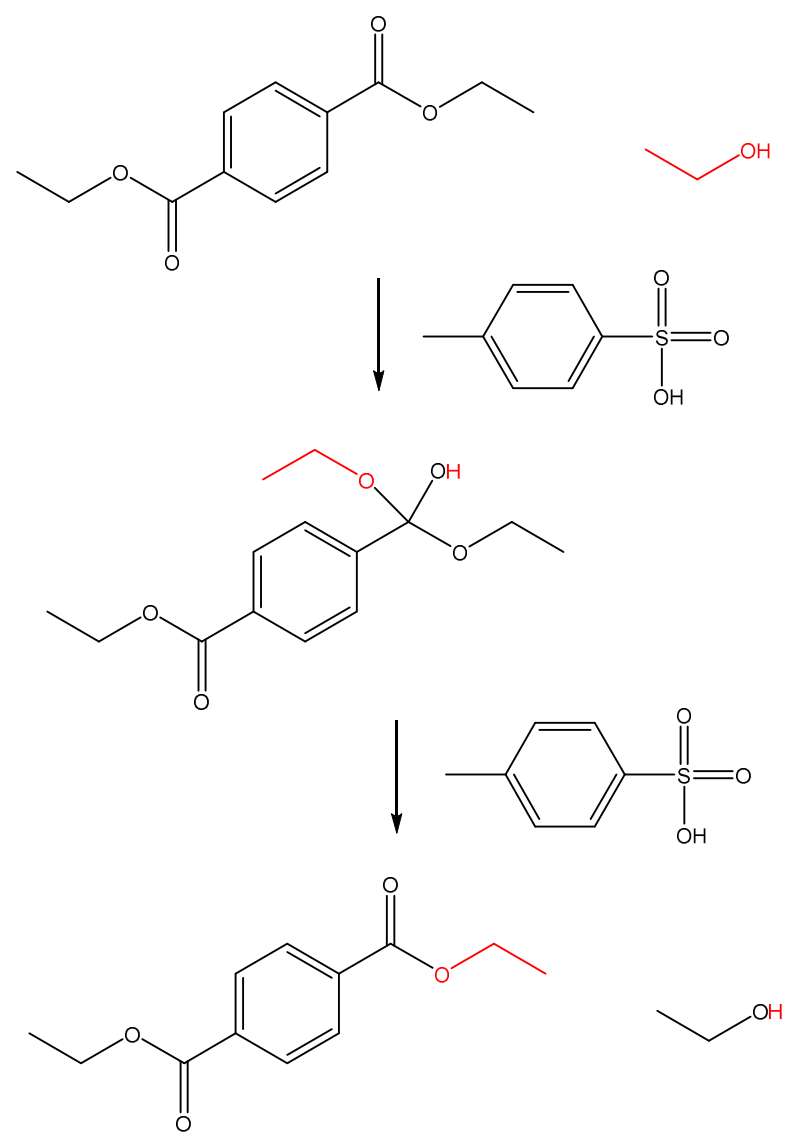

Scheme 4. Transesterification of diethylterephtalate by ethanol

For the first step, leading to the ethyl 4-(diethoxy(hydroxy)methyl)benzoate intermediate, three plausible mechanisms based on the activation of the carbonyl by the acidic proton were considered 
(Scheme 5). In Mec1, the simultaneous activation of the proton of the initiator by the $[\mathrm{S}]=\mathrm{O}$ moieties is proposed, while a second bi-functional mechanism combining the activation of the proton of the initiator by the oxygen of the [S]-O-H moiety is depicted as Mec3. Mec2 corresponds to the mono-functional activation mechanism. For sake of comparison, the calculation without catalyst i.e. the direct attack of the ethanol oxygen to the carbonyl, without the APTS mediation, was also studied.

For the second step, concerning the cleavage of the $\mathrm{C}-\mathrm{O}$ bond of the tetrahedral intermediate and proton transfer, three mechanisms can occur as depicted in Scheme 6. It should be referred that in the global reaction model (Scheme 4) the two steps are symmetric and the final products are the same as the reactants. For this reason, the calculations were restricted to the first step, i.e. the one conducting to the intermediate. The calculated energy profiles, depicted in Figure 2, show that the bi-functional activation pathways have a much lower barrier than the mono-functional. Regarding the former, the simultaneous activation of the proton of the initiator by the $[\mathrm{S}]=\mathrm{O}$ moieties is the most favored, followed by the simultaneous activation of the proton of the initiator by the oxygen of the [S]-O-H moiety. The mono-functional activation, i.e the activation of the carbonyl by the acidic proton mechanism shows a barrier height of the same magnitude of that of the reaction conducted without catalyst. 


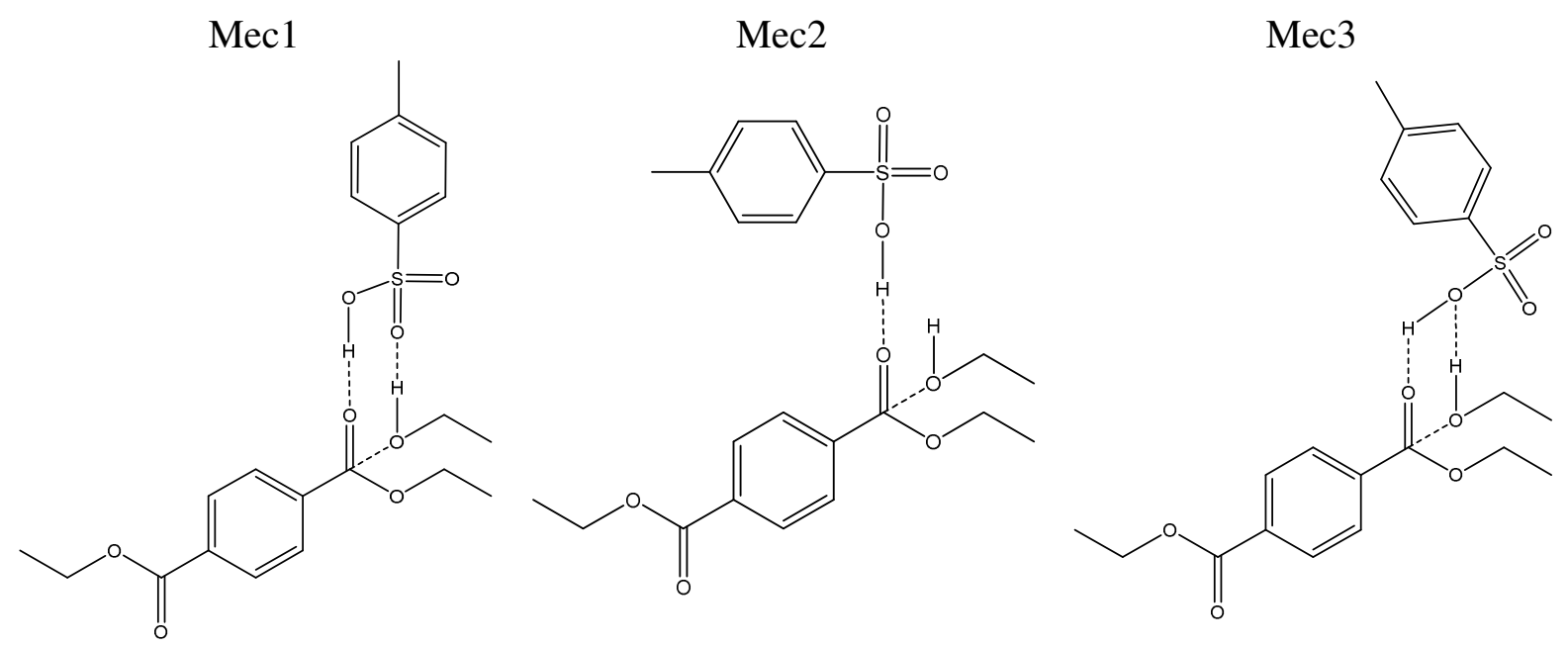

Scheme 5. The possible pathways of the reaction first step: Mec1 - simultaneous activation of the proton of the initiator by the $[\mathrm{S}]=\mathrm{O}$ moieties, Mec 2 - activation of the carbonyl by the acidic proton only and Mec 3 - simultaneous activation of the proton of the initiator by the oxygen of the $[\mathrm{S}]-\mathrm{O}-\mathrm{H}$ moiety. 

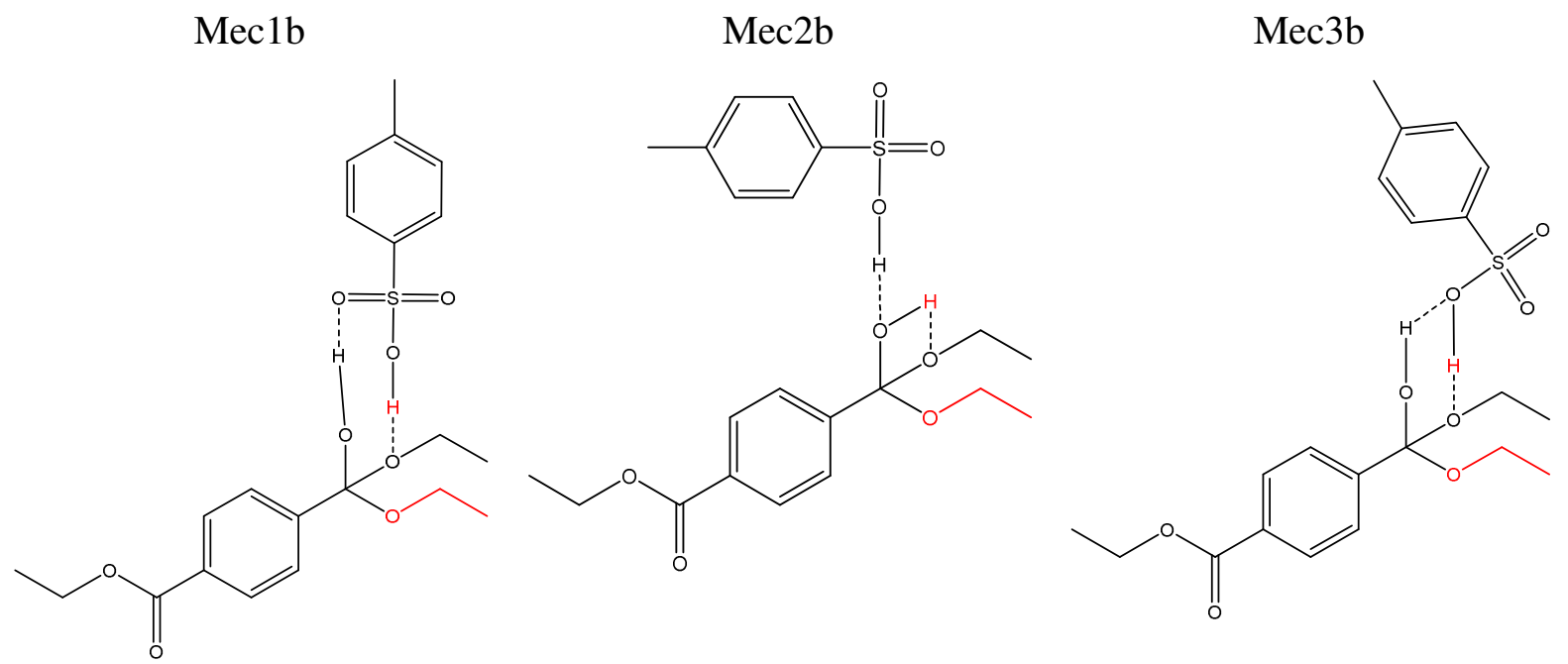

Scheme 6. Considered pathways of the reaction second step

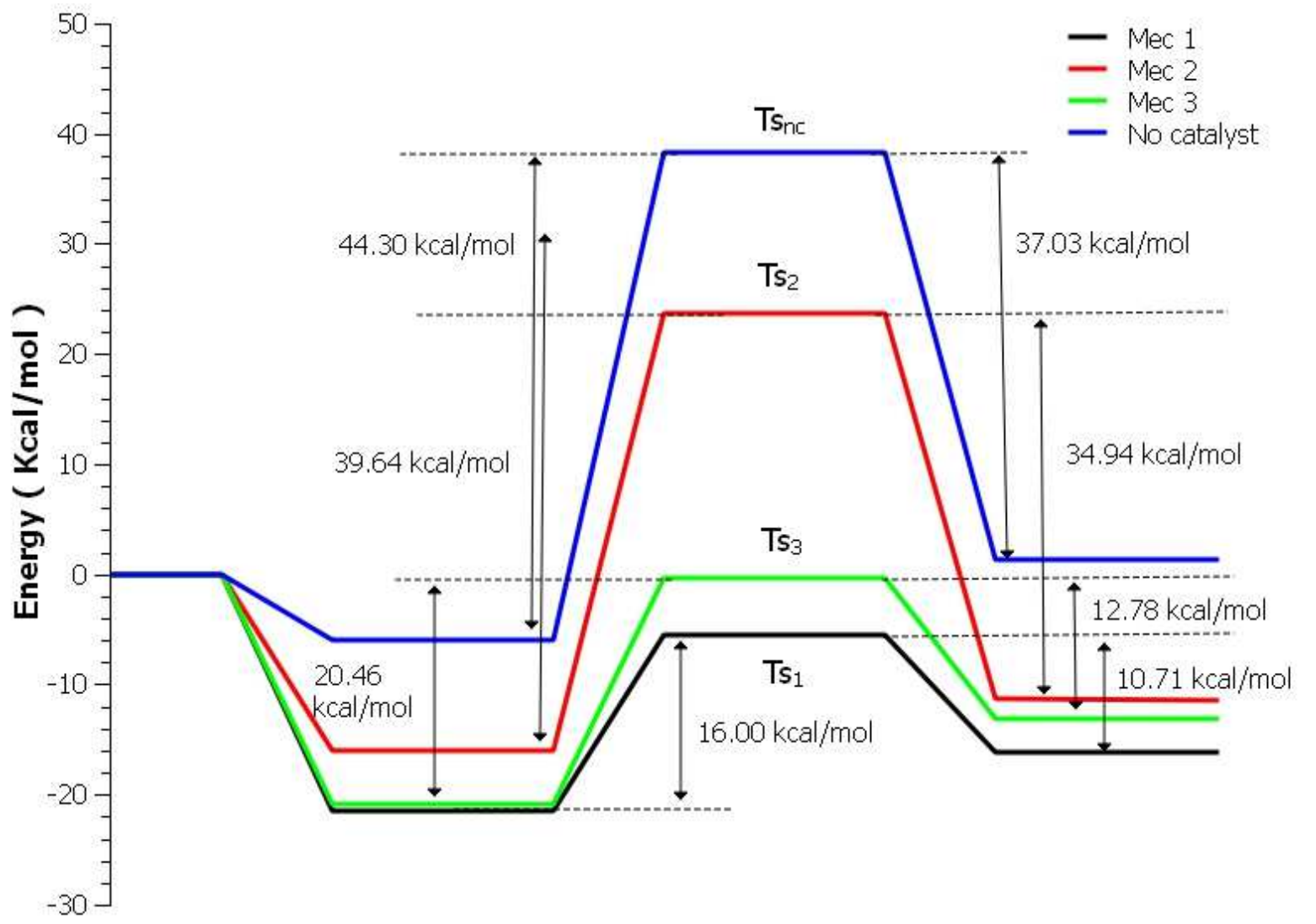

Figure 2. Reaction profile of the different pathways for the the transesterification of diethylterephtalate by ethanol, catalysed by APTS. 
Figure 3 illustrates the structures of the reactant complexes, transition states and product adducts of the different pathways studied. In the non-catalysed mechanism, the ethanol hydrogen directly activates the carbonyl group through hydrogen bonding $(\mathrm{OH} \cdots \mathrm{OC}$ bond distance $=1.97 \AA)$ while the ethanol oxygen attacks the electrophilic carbon of the diethylterephtalate carbonyl group. This occurs simultaneously with the proton transfer, forming the intermediate with a tetrahedral center at the carbon accompanied with an increasing of the carbonyl C-O bond length (from $1.22 \AA$ to $1.39 \AA)$ and the formation of an O-H bond $(0.97 \AA)$. In the catalyst driven mechanisms, the catalyst holds the reactants in favourable positions for nucleophilic attack, by means of hydrogen bonds. Regarding the bi-functional activation pathways, in Mec1the catalyst stabilizes the reactants by means of two hydrogen bonds; one where one oxygen acts as a $\mathrm{H}$-bond acceptor $(\mathrm{OH} \cdots \mathrm{OS}$ bond distance $1.91 \AA$ ) and another in which a distinct oxygen acts as a $\mathrm{H}$-bond donor $(\mathrm{OH} \cdots \mathrm{OC}$ bond distance $1.73 \AA$ ). In the Mec3 case only one catalyst oxygen acts both as H-bond donor (OH $\cdots \mathrm{OC}$ bond distance $1.70 \AA$ ) and acceptor ( $\mathrm{OH}^{\cdots}$ OOS bond distance $2.01 \AA$ ). These interactions stabilize the reactive species in favourable positions for the nucleophilic attack, particularly in the configuration of Mec1, where the distance between the alcohol oxygen and the carbonyl electrophilic carbon is $2.62 \AA$, while in Mec3 the reactants/catalyst adduct distance is $2.72 \AA$. While in Mec1 and Mec3, both the carbonyl and the alcohol reagents are hydrogen bonded with the APTS catalyst, in Mec2, only the carbonyl oxygen interacts with it ( $\mathrm{OH} \cdots \mathrm{OS}$ bond distance $1.71 \AA$ ). This suggests that the activation of the alcohol reagent is important to lower the barrier and facilitate the nucleophilic attack on the carbon carbonyl. On the other hand, the similarity between the Mec2 barrier and the non-catalysed mechanism barrier suggests that the carbonyl activation by the APTS catalyst has a minor importance to facilitate the attack on the carbon carbonyl. There is additionally an important difference between Mec1 and Mec3 when compared with Mec2 and also with the non-catalysed mechanism. In the latter the alcohol hydrogen is transferred directly to the hydrogen 
carbonyl while in the former mechanisms the alcohol hydrogen is transferred to the catalyst that gives its own hydrogen to the activated carbonyl group. The results shows that the pathways involving the change of hydrogen between the reactants and the catalyst present a much smaller energy barrier and consequently are more favourable. p-toluene sulfonic acid acts thus as a "proton shuttle" via its acidic proton and basic oxygen. Similar behaviours were observed in other sulfonic acid catalysed reactions ${ }^{[44-45]}$ and notably lactone ring opening polymerization. ${ }^{[43]}$ For the second step when the cleavage of the $\mathrm{C}-\mathrm{O}$ bond of the tetrahedral intermediate and a proton transfer occurs, the barriers are all smaller then for the first step, due to the lower stability of the intermediate adducts when compared with the initial reactants complexes. The smaller barriers correspond to the mechanisms in which a change of hydrogens between the reactants and the APTS catalyst occurs i.e. the pathways Mec1b and Mec3b. 
Mec 1
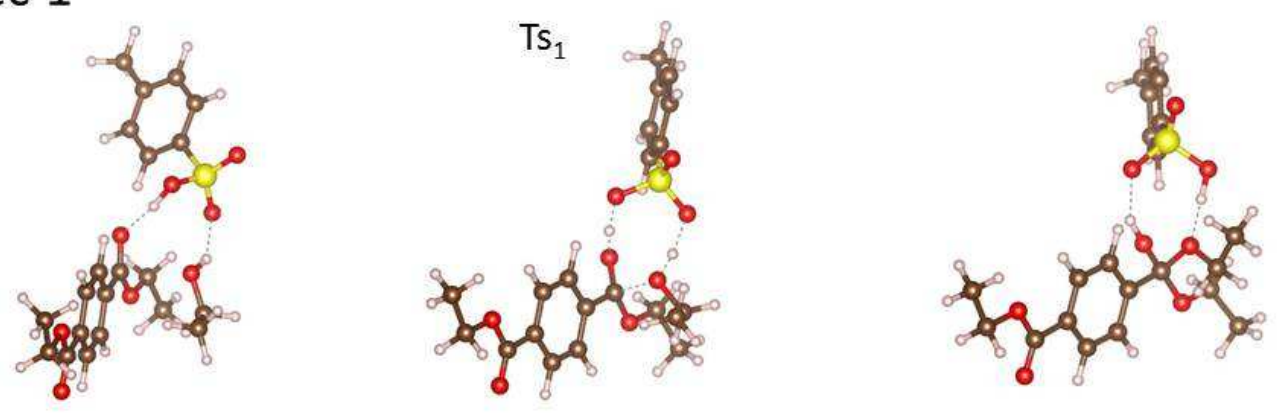

Mec 2

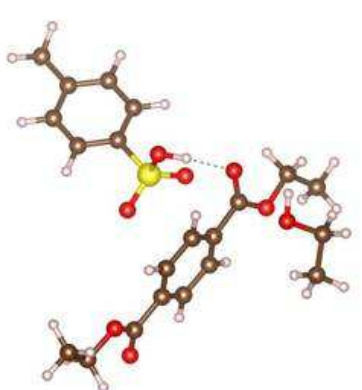

$\mathrm{Ts}_{2}$
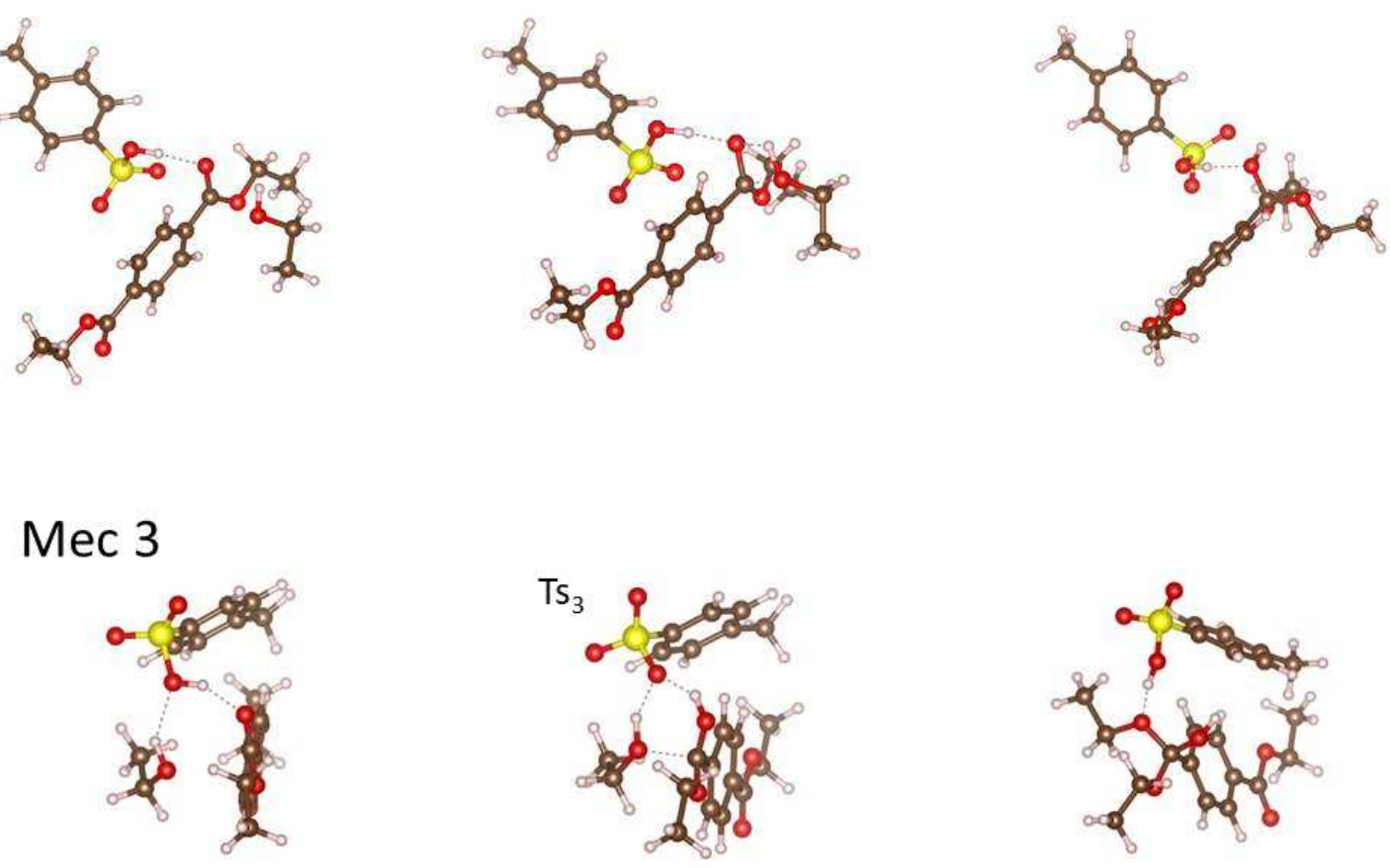

No catalyst
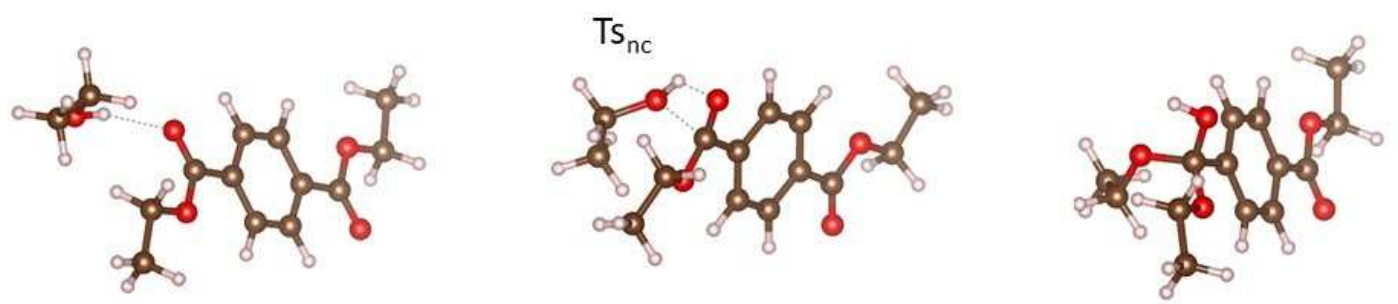

Figure 3. Structures of the reactant complexes, transitions state and product adducts of the different pathways studied 
Three different bases, i.e an amidine, a guanidine and a phosphazene were further assessed at 2 mol\% (entries 8, 9 and 10 respectively). Carbenes were not considered as potential catalysts, as they are not stable at high temperatures. BEMP was selected as it has an average pKa phosphazene. Reactions conducted with DMAP did not lead to polymerization activities. DBU and TBD led to molecular weights of $c a .17000$ and $23000 \mathrm{~g} / \mathrm{mol}$, respectively, following the pKa values of the bases (24.3 and 26.0 respectively in acetonitrile $\left.{ }^{[46]}\right)$. It should also be noted that, in contrast to DBU where basic and nucleophilic catalytic mechanisms can operate, TBD is able to catalyse transesterification reactions via a dual activation involving H-bonding. ${ }^{[47-48]}$ A higher glass transition temperature is obtained using TBD, which may be ascribed to the higher molecular weight. This is accompanied by a higher coloration, as noticed from the higher yellowing index measured. The phosphazene, with a higher pKa value of 27.6 in acetonitrile, ${ }^{[49]}$ leads in turn to number-average molecular weight lower than that of the blank (entry 1). This highlights substantial degradation reactions using this catalyst. Regarding the polymer microstructure, the isosorbide content is similar whatever the nature of the base, and is also close to that observed with the acids. It is however noteworthy that the amount of DEG in the final products is considerably lower using basic organocatalysts. This further proves that the high DEG content is linked to acid catalysis.

Different types of transesterification mechanisms can be considered in the presence of such nitrogeneous bases. They can be distinguished by the first step : a nucleophilic attack of the catalyst or a basic activation of the alcohol, eventually accompanied by an hydrogen bond activation of the carbonyl moiety in the case of TBD. They are represented in Table 2 . The mechanism of a TBD catalysed alkyl benzoate / alcohol transesterification, which is considered as a model in the present work, has been studied theoretically. ${ }^{[30]}$ The pathway involving the alcohol activation concomitant with H-bond activation of the carbonyl moiety (Table 2, down right corner) was found to occur 
preferentially, with a significant difference of $c a .9 \mathrm{kcal}$ between the highest energy barrier of the reaction profiles. Similar trends were reported for the TBD catalysed ring-opening polymerization of lactide, which is also a transesterification reaction. ${ }^{[47-48]}$ The DBU catalysed ring opening polymerization of lactide was in turn found to be able to occur via both nucleophilic and alcohol activation pathways. ${ }^{[50-51]}$ The comparison / discrimination between the nucleophilic and the alcohol activation mechanism in the course of a DBU catalysed alcohol / alkylbenzoate transesterification has in turn not been assessed by DFT has far as we know, and is reported hereafter.

In the nucleophilic pathway (Table 2, up left corner), at the first step of the reaction, the DBU catalyst bound covalently to the ester. The barrier for this step (figure 4, top) is substantial ( 45 $\mathrm{kcal} \mathrm{mol}^{-1}$ ) as well as the barrier height of the second step, when the alcohol is released and makes this pathway highly unprobable. For the TBD catalysed reaction, a higher energy barrier was also found for the nucleophilic pathway when compared with the H-bond pathway, ${ }^{[30]}$ although substantially lower than the one involving DBU as the catalyst. The structures of the reactant complexes, transitions state and product adducts of the nucleophilic mechanism of the DBU catalysed pathway are presented Figure 4, bottom. In this mechanisms, the catalyst attacks the carbonyl carbon in $\mathrm{Ts}_{1}$ and covalently bonds the ester, while simultaneously the carbonyl carbon oxygen bond of the reactant breaks and the ethoxy group also bonds covalently to the catalyst. In the second step, $\mathrm{Ts}_{2}$ involves the transfer of a proton in the catalyst to the leaving ethanol molecule, with the breaking of the $\mathrm{C}-\mathrm{O}$ bond formed in the previous step. Note that the second step of the reaction to release the transesterification product is not included because in the model reaction the pathways are symmetric and the products are equivalent to the reactants. 


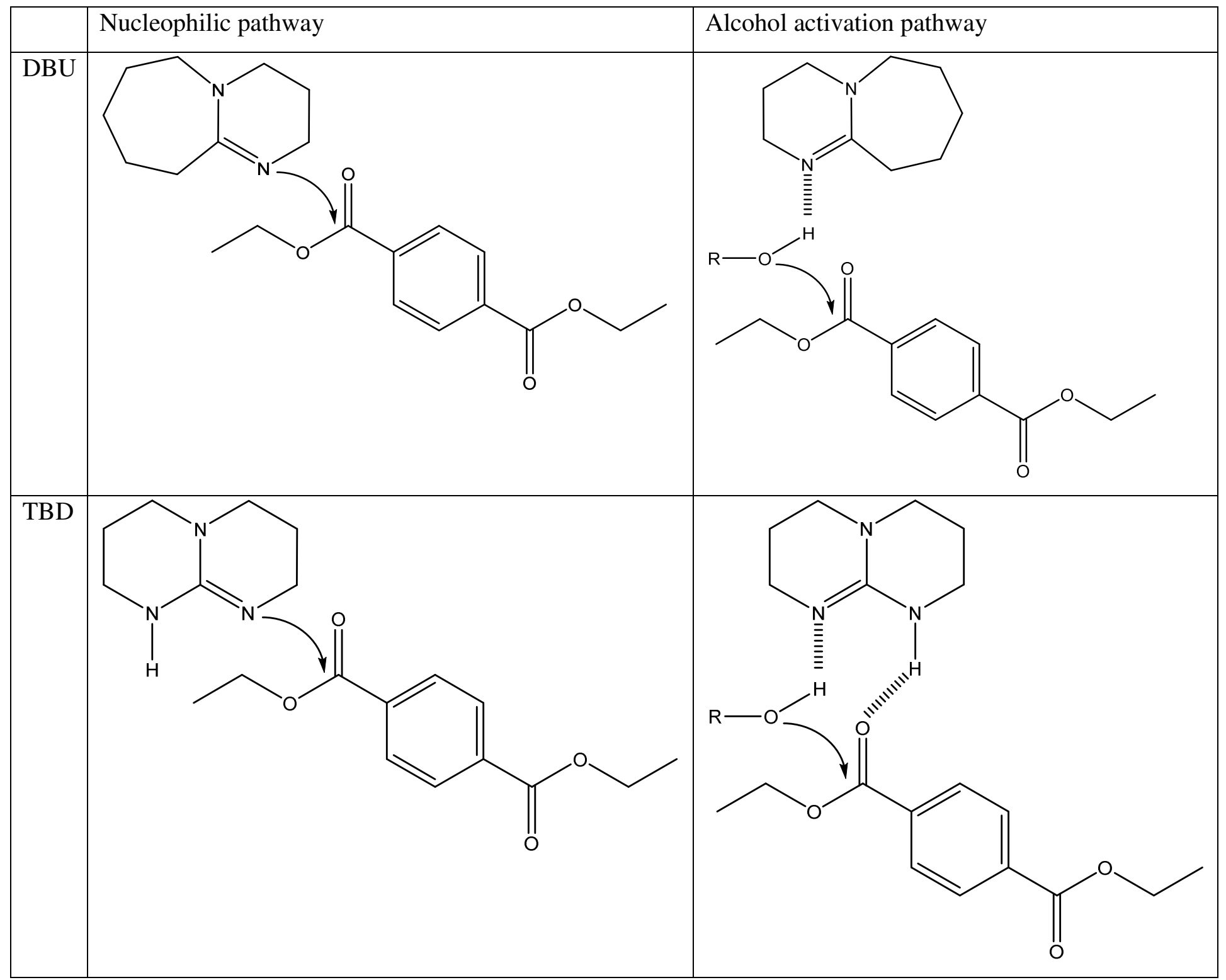

Table 2. Initial steps for the DBU and TBD catalysed transesterification 


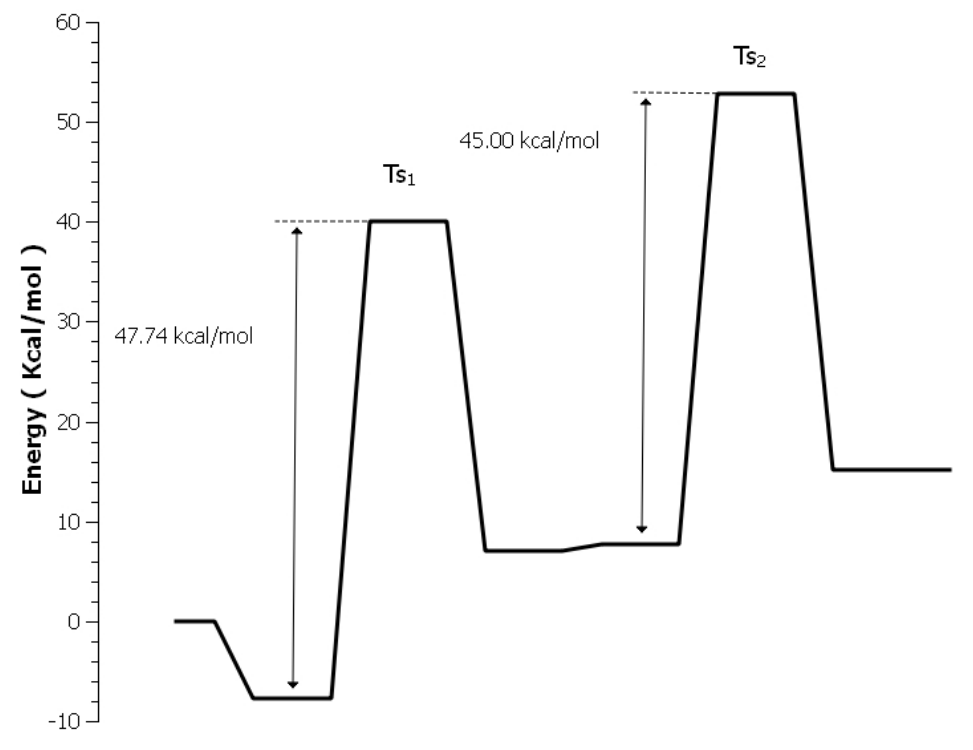

\section{Step 1}
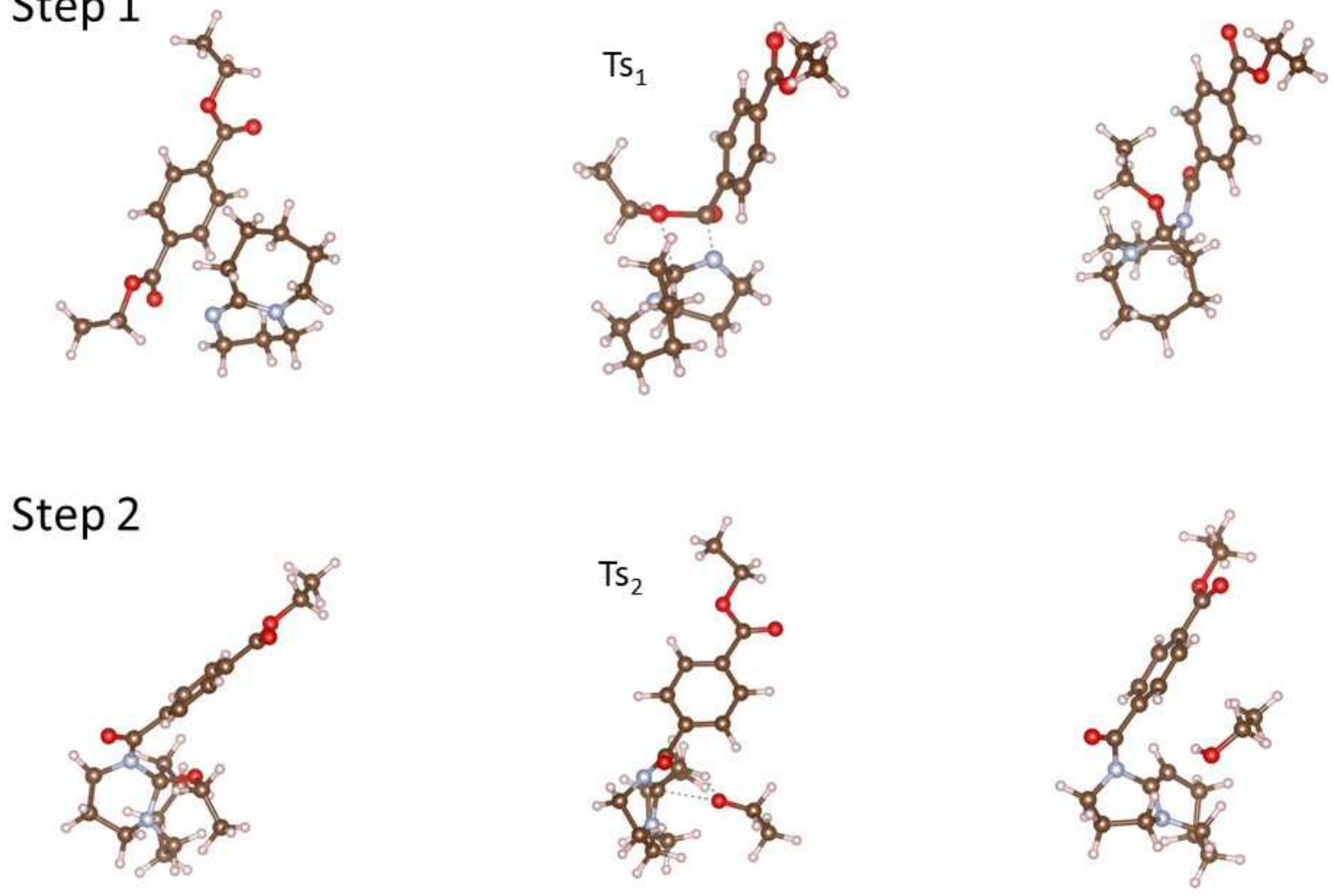

Figure 4. Reaction profile of the nucleophilic mechanism of the DBU catalysed alcohol / alkylbenzoate transesterification (top) and the structures of the corresponding reactant complexes, transitions states and product adducts (bottom). 
The hydrogen bonding pathway (Table 2, up right corner) that involves the alcohol activation occurs with a barrier significantly lower than that corresponding to the nucleophilic attack and should occur preferentially (figure 5, top). The equivalent mechanism using TBD as catalyst ${ }^{[30]}$ seems to have a smaller barrier than that obtained for DBU, confirming that TBD is a more efficient catalyst for this reaction.

The structures of the reactant complexes, transitions state and product adducts of the alcohol activation mechanism of the DBU catalysed pathway are depicted in Figure 5, bottom. The catalyst activates the alcohol through hydrogen bonding $(\mathrm{N} \cdots \mathrm{HO}$ bond distance $=1.85 \AA$ ), during the nucleophilic attack, leading to an intermediate product only slightly more stable than the transition state, with a tetrahedral carbon that results from the formation of a new single $\mathrm{O}-\mathrm{C}$ bond, which is accompanied to an expected increasing of the carbonyl C-O bond length (from $1.21 \AA$ to $1.27 \AA$ ). This tetrahedral intermediate presents a negative charge at the carbonyl oxygen, stabilized by the protonated DBU positively charged nearby. In the equivalent TBD catalysed mechanism, the carbonyl oxygen is further stabilized by the TBD amine hydrogen, a bi-functional interaction that DBU is unable to provide. The calculations suggest thus that DBU is less efficient than TDB as a catalyst probably due to the fact that the latter allows a simultaneous alcohol and $\mathrm{C}=\mathrm{O}$ activation via H-bonding on two different sites.

Finally, antimony oxide, which is commonly used on an industrial scale for the synthesis of PET was assessed in similar conditions (entry 11) for the sake of comparison. DEG amounts are similar to those obtained using TBD or DBU, and the resulting molecular weight is slightly higher. This latter point might be balanced by the solid state polycondensation step (see Scheme 2, third step.). 

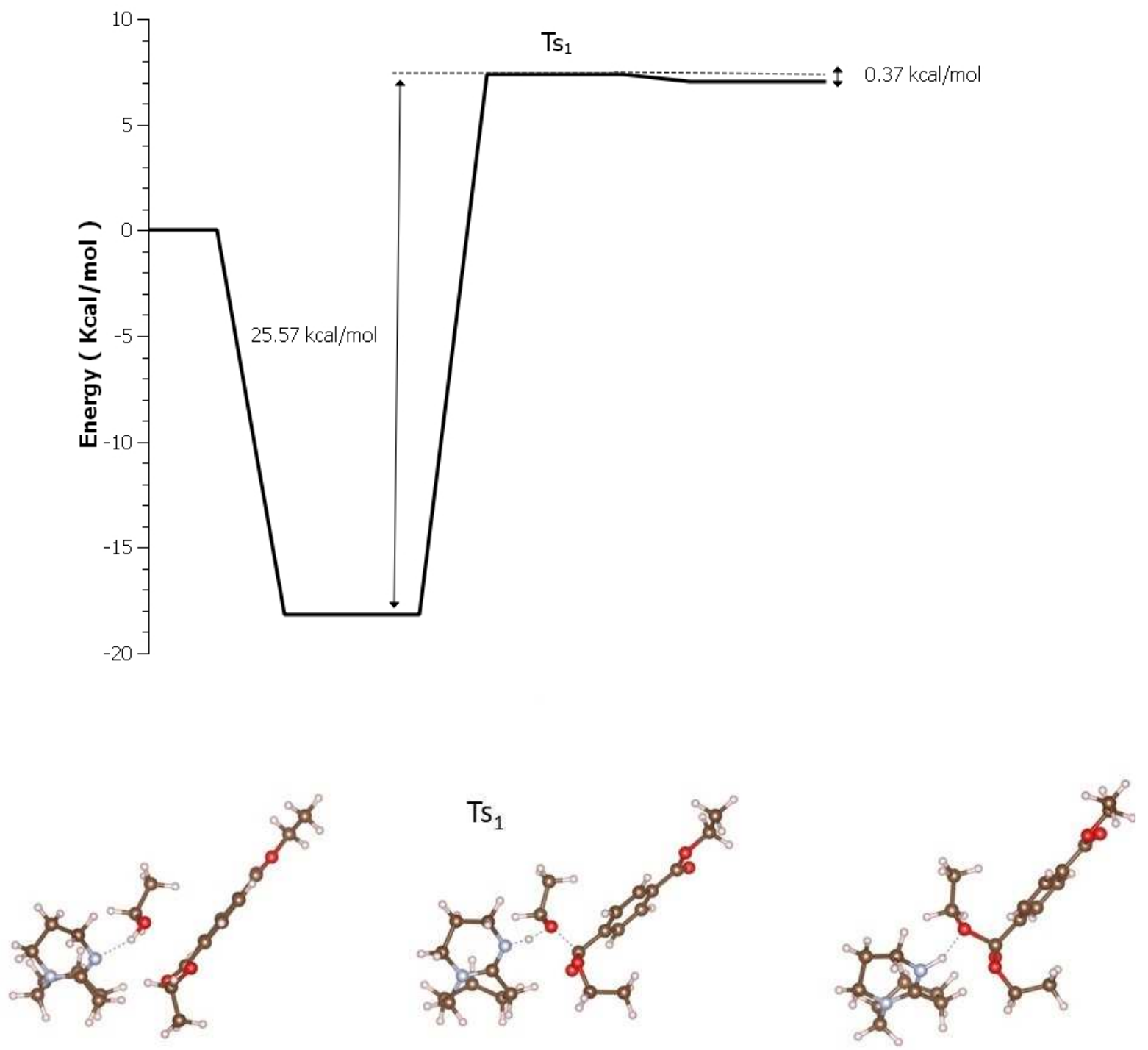

Figure 5. Reaction profile of alcohol activation mechanism of the DBU catalysed alcohol / alkylbenzoate transesterification (top) and the structures of the corresponding reactant complexes, transitions states and product adducts. 


\section{Conclusion}

Organocatalysts were assessed for the synthesis of poly(ethylene terephthalate- $c o$-isosorbide terephthalate). The highest molecular weight were obtained using $p$-toluene sulfonic acid and the TBD guanidine. The polymers obtained with these catalysts have substantial colouration, and the sulfur based catalyst leads to polymers with a high DEG content. A good compromise is brought by the use of the DBU amidine, with acceptable molecular weights, low coloration and low amounts of ether links in the backbone. When the phosphorous species were used in quantities of $5 \mathrm{~mol} \%$, insoluble polymers were obtained possibly resulting from a cross-linking reaction. The reaction mechanisms were studied by DFT. Bi-functionnal activation mechanisms were found for both acid and base catalysts. A proton shuttling role of the sulfonic acid was evidenced, with a simultaneous acid activation of the carbonyl and basic activation of the alcohol through the $\mathrm{S}=\mathrm{O}$ moiety for the latter. A concomitant basic activation of the alcohol together with a DBU-Hcarbonyl interaction was found for the DBU.

\section{Appendix.}

From protons 2 and 5: $\mathrm{Isb}(4 \mathrm{H})=2 * 4.64=9.28$

From protons D: $\mathrm{DEG}(4 \mathrm{H})=10.66$

From protons 4, B and $\mathrm{C}: \mathrm{EG}(4 \mathrm{H})+\mathrm{Isb}(1 \mathrm{H})+\mathrm{DEG}(4 \mathrm{H})=100$

$\operatorname{Isb}(1 \mathrm{H})=\operatorname{Isb}(4 \mathrm{H}) / 4=2.32$

Thus EG(4H) $=100-10.66-2.32=87.02$

$\mathrm{EG}(4 \mathrm{H})+\mathrm{Isb}(4 \mathrm{H})+\mathrm{DEG}(4 \mathrm{H})=106.96$

$\operatorname{Isb}(\%)=9.28 / 106.96 * 100=8.7$

$\operatorname{DEG}(\%)=10.66 / 106.96 * 100=10.0$ 


\section{Acknowledgments}

This project is supported by the French State as part of the "Programme d'Investissement d'Avenir", under reference ANR-10-IEED-0004-01. Chevreul Institute (FR 2638), Ministère de l'Enseignement Supérieur et de la Recherche, Région Hauts de France and FEDER are acknowledged for supporting and funding partially this work.

Keywords : polymerisation, organocatalysis, DFT, mechanism, isosorbide

\section{Collected references}

1. B. A. Noordover et al., Biomacromolecules 2006, 7, 3406.

2. L. Sipos et al., WO Pat. 20151421812015.

3. G. Z. Papageorgiou, D. G. Papageorgiou, Z. Terzopoulou, D. N. Bikiaris, Eur. Polym. J. 2016, $83,202$.

4. Z. Terzopoulou et al., Materials 2017, 10, 801.

5. J.-D. Rodier et al., J. Polym. Sci. Part Polym. Chem. 2017, 55, 2178.

6. R. Medimagh et al., Comptes Rendus Chim. 2007, 10, 234.

7. S. Chatti, G. Schwarz, H. R. Kricheldorf, Macromolecules 2006, 39, 9064.

8. S. Chatti, H. R. Kricheldorf, G. Schwarz, J. Polym. Sci. Part Polym. Chem. 2006, 44, 3616.

9. B. A. J. Noordover, D. Haveman, R. Duchateau, R. A. T. M. van Benthem, C. E. Koning, J. Appl. Polym. Sci. 2011, 121, 1450.

10. R. M. Gohil, Polym. Eng. Sci. 2009, 49, 544.

11. R. Quintana, A. martínez de Ilarduya, A. Alla, S. Muñoz-Guerra, J. Polym. Sci. Part Polym. Chem. 2011, 49, 2252.

12. R. Quintana, A. M. d. Ilarduya, A. Alla, S. M. Guerra, High Perform. Polym. 2012, 24, 24. 
13. W. J. Yoon et al., Macromolecules 2013, 46, 7219.

14. J. M. Koo et al., Polym Chem 2015, 6, 6973.

15. F. Fenouillot, A. Rousseau, G. Colomines, R. Saint-Loup, J.-P. Pascault, Prog. Polym. Sci. 2010, 35, 578 .

16. J. C. Bersot et al., Macromol. Chem. Phys. 2011, 212, 2114.

17. N. Stanley et al., Polymers 2017, 9, 590.

18. M. L. C. M. Henckens, P. P. J. Driessen, E. Worrell, Resour. Conserv. Recycl. 2016, 108, 54.

19. N. E. Kamber et al., Chem. Rev. 2007, 107, 5813.

20. M. K. Kiesewetter, E. J. Shin, J. L. Hedrick, R. M. Waymouth, Macromolecules 2010, 43, 2093.

21. A. P. Dove, ACS Macro Lett. 2012, 1, 1409.

22. C. Thomas, B. Bibal, Green Chem. 2014, 16, 1687.

23. W. N. Ottou, H. Sardon, D. Mecerreyes, J. Vignolle, D. Taton, Prog. Polym. Sci. 2016, 56, 64.

24. J. Alsarraf et al., Macromolecules 2012, 45, 2249.

25. O. Coutelier et al., Polym. Chem. 2012, 3, 605.

26. H. Sardon et al., J. Am. Chem. Soc. 2013, 135, 16235.

27. H. Sardon, J. M. W. Chan, R. J. Ono, D. Mecerreyes, J. L. Hedrick, Polym Chem 2014, 5, 3547.

28. M. Ajioka, K. Enomoto, K. Suzuki, A. Yamaguchi, Bull. Chem. Soc. Jpn. 1995, 68, 2125.

29. H. Iwahashi, T. Oka, A. Abiko, Chem. Lett. 2008, 37, 708.

30. K. Fukushima et al., J. Polym. Sci. Part Polym. Chem. 2011, 49, 1273.

31. G. W. Nyce, J. A. Lamboy, E. F. Connor, R. M. Waymouth, J. L. Hedrick, Org. Lett. 2002, 4, 3587.

32. I. Flores et al., Eur. Polym. J. 2018, 104, 170.

33. K. T. Park,, J. R. Kim, WO2010/076981 2011. 
34. N. Jacquel, R. Saint-Loup, WO2016066956 2016.

35. M. J. Frisch et al., 2016.

36. Y. Zhao, D. G. Truhlar, Theor. Chem. Acc. 2008, 120, 215.

37. I. Seganov, J. M. Schultz, S. Fakirov, J. Appl. Polym. Sci. 1986, 32, 3371.

38. G. Karayannidis et al., Angew. Makromol. Chem. 1993, 208, 117.

39. J. T. Muckerman, J. H. Skone, M. Ning, Y. Wasada-Tsutsui, Biochim. Biophys. Acta BBA Bioenerg. 2013, 1827, 882.

40. J. Pretula et al., J. Polym. Sci. Part Polym. Chem. 2006, 44, 2358.

41. J. Pretula et al., J. Polym. Sci. Part Polym. Chem. 2008, 46, 830.

42. I. Shigemoto, T. Kawakami, H. Taiko, M. Okumura, Polymer 2011, 52, 3443.

43. N. Susperregui, D. Delcroix, B. Martin-Vaca, D. Bourissou, L. Maron, J. Org. Chem. 2010, 75,6581 .

44. M. Jacobsson et al., Chem. - Eur. J. 2008, 14, 3954.

45. X. Li, S. Ye, C. He, Z.-X. Yu, Eur. J. Org. Chem. 2008, 2008, 4296.

46. I. Kaljurand et al., J. Org. Chem. 2005, 70, 1019.

47. L. Simón, J. M. Goodman, J. Org. Chem. 2007, 72, 9656.

48. A. Chuma et al., J. Am. Chem. Soc. 2008, 130, 6749.

49. R. Schwesinger, H. Schlemper, Angew. Chem. Int. Ed. 1987, 26, 1167.

50. H. A. Brown, A. G. De Crisci, J. L. Hedrick, R. M. Waymouth, ACS Macro Lett. 2012, 1, 1113.

51. N. J. Sherck, H. C. Kim, Y.-Y. Won, Macromolecules 2016, 49, 4699. 

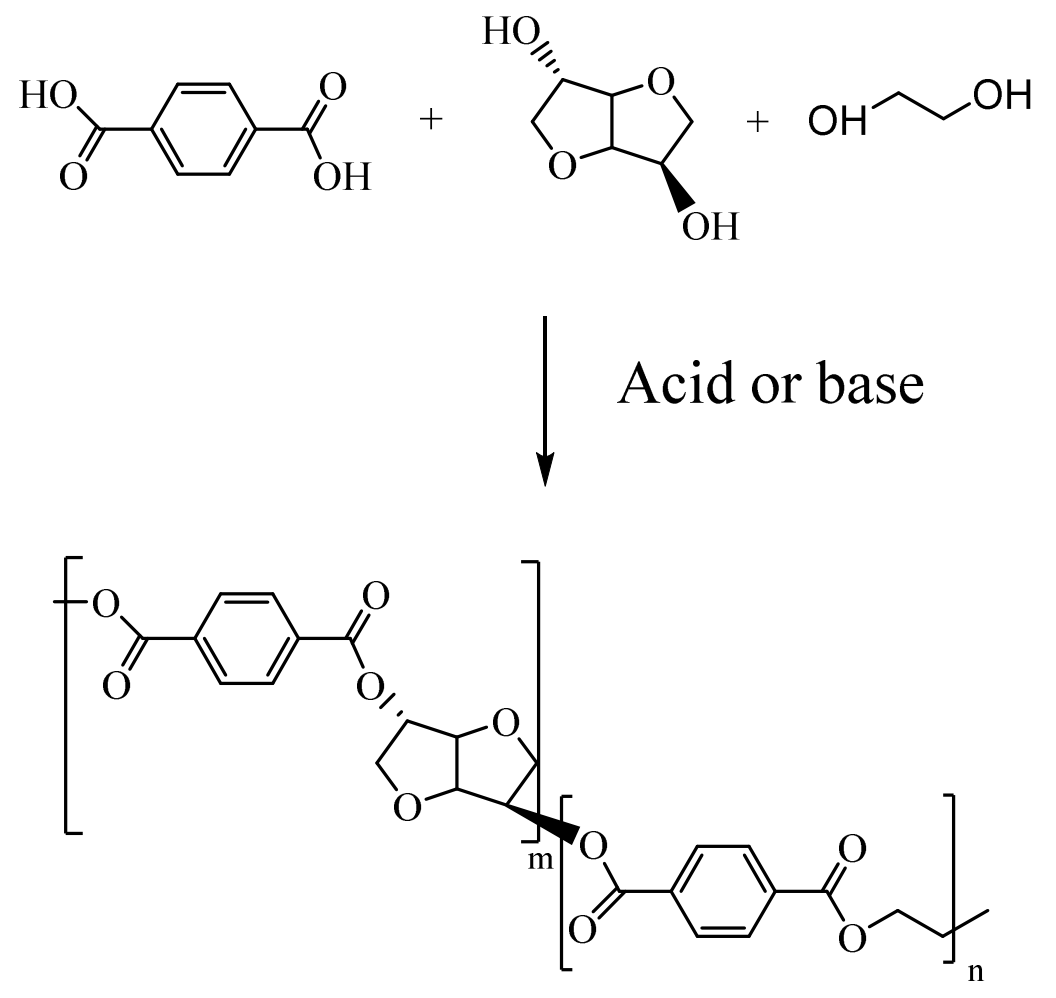

Organocatalysts have been successfully assessed for the insertion of isosorbide into PET (polyethylene terephthalate). The reaction mechanisms are studied by DFT. 